\title{
Malignant mesothelioma: incidence, asbestos exposure, and reclassification of histopathology
}

\author{
W E WRIGHT, ' $R$ P SHERWIN, ${ }^{2}$ ELIZABETH A DICKSON, ' L BERNSTEIN,' JANINE \\ B FROMM, ${ }^{*}$ AND B E HENDERSON ${ }^{1}$
}

From the Department of Family and Preventive Medicine, ${ }^{1}$ and the Department of Pathology, ${ }^{2}$ University of Southern California School of Medicine, Los Angeles, California 90033, USA

ABSTRACT The Los Angeles County Cancer Surveillance Program abstracts records on almost all cases of cancer occurring in the county. In a study of those cases of pleural and peritoneal malignant mesothelioma (MM) that occurred from 1972 to 1979 occupational histories were obtained during interviews, and histopathology of the tumours was reviewed and classified by a member of a mesothelioma reference panel who was unaware of the exposure histories. About half the cases reviewed had likely exposure to asbestos at work. The greatest proportion of cases designated as MM by the pathologist occurred among individuals likely to have had the heaviest exposure of asbestos (42\%). No upward trend of incidence over time was apparent among cases designated as MM. The age adjusted incidence rates for designated MM were lower than in other studies. The well recognised interobserver variability in diagnosing MM apparently produces raised estimates of incidence and an overestimate of trends of incidence. The interobserver variability may result from different awareness of MM occurrence, a lack of precise histopathological criteria for the diagnosis, or the influence of a history of exposure to asbestos on the interpretation. A history of exposure to asbestos may bias interpretation of histopathology and should not be used to make the histological diagnosis.

Malignant mesothelioma is a rare tumour strongly associated with exposure to asbestos. It has become a public health concern because of extensive occupational and environmental sources of asbestos, and an apparent trend of increasing incidence. ${ }^{12}$ The incidence of mesothelioma has been difficult to establish with certainty. The histopathological features of mesothelioma have not been clearly distinguished from those of other cancers (primarily adenocarcinoma) and the diagnosis has been applied to benign varieties of pleural proliferation. In addition, malignant mesothelioma as a cause of death has only recently been routinely coded for summary statistics of death certificates. ${ }^{3}$

The effect that the misclassification of mesothelioma has on population based incidence data is not clear. To help describe the extent and effect of misclassification of this tumour, we have

${ }^{*}$ Dr Fromm is a resident at the University of California at San Francisco.

Received 9 November 1982

Accepted 10 January 1983 studied the incident cases of malignant mesothelioma diagnosed by pathologists in Los Angeles County. The present paper describes a re-evaluation of the histopathology of tumours reported to be mesotheliomas and relates the reclassified histopathology to asbestos exposure and incidence.

\section{Methods}

\section{CASE SELECTION}

Cases of mesothelioma from ICD-O (1976) sites 163 (pleural) and 158 (peritoneal), excluding benign mesotheliomas, first diagnosed by pathologists in Los Angeles County between 1972 and 1979, were gathered using the Los Angeles County Cancer Surveillance Program (CSP), a population based cancer registry. ${ }^{45}$ The registry achieves nearly complete ascertainment of the incidence of cancer (excluding skin cancer) in Los Angeles County. Cases were identified from hospital pathology records and from the death certificates of Los Angeles County residents. Collection of cases was complete for the years $1972-8$ but owing to delays 
in reporting, only about $60 \%$ of cases that occurred in 1979 were available for inclusion.

\section{SLIDE REVIEW}

Slides and paraffin blocks for each case were requested from the pathology department of each hospital at which a case was diagnosed. The slides and paraffin blocks were examined and classified by a member (RPS) of the UICC United States mesothelioma reference panel. No clinical or exposure information was available to the pathologist. Each case for which tissue was received was classified into one of the following seven categories: (1) confident ("definite") diagnosis of mesothelioma; (2) probable mesothelioma; (3) possible mesothelioma (equivocal tumour, mesothelioma, and other cancer equally favoured); (4) unlikely mesothelioma (other cancer favoured); (5) confident not ("definitely not") pleural or peritoneal mesothelioma (other cancer); (6) mesothelioma other than usual malignant variety (including benign and malignant varieties of subpleural fibroma, adenomatous and other types of genital tract tumours, and unicentric and multicentric mesothelial hyperplasias); and (7) material received inadequate for histopathological interpretation.

The gross and microscopic characteristics favouring an interpretation of mesothelioma were: (1) restriction of the cancer to a diffuse, plaquelike proliferation of the pleural or peritoneal surface; (2) necropsy exclusion of a primary site other than the mesothelium; (3) histopathological features pathognomonic of mesothelioma, in particular a biphasic pattern, slit formation, and cuboidal cells with centrally placed, round nuclei and with small, uniform nucleoli, or nuclear vacuolisation; (4) histochemical studies indicating intracytoplasmic hyaluronic acid; and (5) electron microscopic demonstration of classic "bushy" microvilli and absence of organelles indicative of other cell types-for example, lamellar bodies and melanosomes.

The gross and microscopic characteristics favouring an interpretation of cancer other than mesothelioma were: (1) multiple organ involvement; (2) histological features "atypical" for mesothelioma, in particular nuclear and cytoplasmic pleomorphism, columnar cells with basally located nuclei, large and single nucleoli, and a single cellular "phase" such as pleomorphic spindle cells of a sarcomatous nature; (3) cytological and histochemical findings indicative or suggestive of mucin.

\section{INTERVIEWS}

The attending physician of each patient was sent a letter requesting permission to contact the case or a close relative listed on the CSP record. After permission was received a letter was sent to the patient, or a relative if the patient had died, requesting a telephone interview. Death certificates of patients, and of their spouse if both had died, were also used to locate a relative for an interview. Mailing addresses were verified by local telephone books, United States Postal Service files, and records from the State of California department of motor vehicles. Patients who refused to be interviewed or who did not respond after three letters had been mailed, and could not be reached by telephone, were considered non-respondents. People for whom neither an address nor a telephone number could be found were considered to be not locatable. A trained interviewer telephoned all respondents and conducted the interview using a questionnaire which included a chronological occupational history and questions about occupational and non-occupational exposures to various chemicals and dusts with specific reference to asbestos.

\section{CLASSIFICATION OF ASBESTOS EXPOSURE}

Cases were classified as exposed to asbestos if they answered yes to a question about work with asbestos. In addition, the occupational histories were assessed for likelihood of exposure to asbestos by one of the authors (WEW) who did not know the pathological diagnosis and histopathology of the cases. Each job was assigned to a category that reflected likelihood of exposure. The categories were: (A) occupations established to represent likely exposure to asbestos ${ }^{36}$ (1) insulation, (2) asbestos production and manufacture, (3) heating trades, (4) shipyards, (5) construction industry, and (B) all other occupations. It was not possible to assess accurately the likelihood of other occupational, take home, avocational, and environmental exposures to asbestos because many interviews were with family members who were not familiar with these aspects of the patients' lives.

\section{ESTIMATES OF INCIDENCE}

Age adjusted incidenced rates were calculated by direct standardisation using 10 year age groups weighted according to the 1970 United States population. Adjustments of the 1970 Los Angeles census data have been made to allow for post census change and undercounting (V S Siegel, annual meeting, Population Association, 1973).

\section{Results}

\section{CASES COLLECTED}

By 1 June 1980, 212 new cases of mesothelioma or malignant mesothelioma had been collected by the 
CSP for 1972-9. All cases were histologically diagnosed by local pathologists except for one which was based on a death certificate.

There were $182(85.9 \%)$ pleural and $30(14.1 \%)$ peritoneal mesotheliomas. Of the 212 tumours, 161 cases $(75.9 \%$ ) were male. Among men $91.3 \%$ of the recorded mesotheliomas originated in the pleura and among women $68.6 \%$ were of pleural origin.

\section{RECLASSIFICATION OF CASES BASED ON HISTOPATHOLOGY}

Of the 212 cases collected, slides or tissue blocks were obtained for $178(84 \%)$. Of these, $162(91 \%)$ were judged to be adequate specimens for our review and the histopathology of these cases (122 men and 40 women) was evaluated. Table 1 shows the results of the evaluation according to the case's sex and tumour site. Our pathologist designated 42 cases $(26 \%)$ as definite, probable, or possible mesothelioma. These cases will be referred to hereafter as the designated cases of mesothelioma. Thirty four men and eight women were in these categories. Forty six men (38\%) and eight women $(20 \%)$ were considered to have tumours from a primary site other than the pleura or peritoneum. For about $30 \%$ of men and women a diagnosis of other cancer was favoured but mesothelioma could not be entirely excluded. This reclassification is based on all cases with adequate histopathology and includes cases for which the local pathologist's diagnosis of mesothelioma may have been equivocal. If those cases that were judged by the pathologist of record to be questionable are excluded the proportion designated as definite, probable, or possible mesothelioma is $35 \%$.

\section{ASSESSMENT OF EXPOSURE}

Physicians granted permission to contact 204 $(96 \cdot 2 \%)$ of the 212 patients identified by the CSP.
Thirteen $(6 \cdot 1 \%)$ could not be located, and 18 $(8.5 \%)$ were non-respondents. Interviews were conducted with 34 who were still living and 139 close relatives of those who had died. Of those interviewed, 103 men and 31 women had adequate slides for histopathological review.

Table 2 relates to likelihood of exposure to asbestos (by assessment of occupational histories) to the reclassified histopathology in the 134 cases with adequate slides and histories. Seventy one (53\%) had probably been exposed to asbestos at work. More men than women were exposed to asbestos $(69 / 103,67 \% v 2 / 31,7 \%)$. The proportion exposed was highest for the cases designated as methelioma $20 / 34(59 \%)$ and was only slightly lower for the cases definitely thought to have other cancers $28 / 52$ $(54 \%)$. The proportion exposed of those in which other cancers were favoured was 18/34 (53\%).

The proportion of subjects exposed was highest in men thought to have mesotheliomas other than the usual malignant variety $5 / 7(71 \%)$. Four of the exposed in this group were considered to have reactive hyperplasia, a possible premalignant condition. The remaining three men and the seven unexposed women with mesothelioma other than the usual malignant variety were considered to have benign subpleural fibromas (5) or mesotheliomas originating from the female genital organs (2).

Of all subjects exposed to asbestos, 20/71 (28\%) were designated as definite, probable, or possible mesothelioma $(19 / 69,28 \%$ for men and $1 / 2$ for women). When exposure to asbestos was assessed according to the response to the question about asbestos exposure, the proportions identified as exposed to asbestos for each site, sex, and histopathological class vary little from the proportions in table 2 .

Table 3 shows that the proportion of cases designated as definite, probable, and possible

Table 1 Reclassification of histopathology of 212 cases of malignant mesothelioma collected by the Los Angeles County Cancer Surveillance Program by sex and primary site 1972-9

\begin{tabular}{|c|c|c|c|c|c|}
\hline & \multicolumn{2}{|l|}{ Men } & \multicolumn{2}{|l|}{ Women } & \multirow[b]{2}{*}{ Total } \\
\hline & Pleural & Peritoneal & Pleural & Peritoneal & \\
\hline $\begin{array}{l}\text { Mesothelioma } \\
\text { "Definite" } \\
\text { Probable } \\
\text { Possible (equivocal) }\end{array}$ & $\begin{array}{r}4 \\
9 \\
17\end{array}$ & $\begin{array}{l}0 \\
3 \\
1\end{array}$ & $\begin{array}{l}0 \\
1 \\
4\end{array}$ & $\begin{array}{l}0 \\
2 \\
1\end{array}$ & $\begin{array}{r}4 \\
15 \\
23\end{array}$ \\
\hline $\begin{array}{l}\text { Mesothelioma } \\
\text { Other than usual malignant variety }\end{array}$ & 7 & 1 & 7 & 4 & 19 \\
\hline $\begin{array}{l}\text { Other cancer } \\
\text { Favoured } \\
\text { "Definite" } \\
\text { Subtotal }\end{array}$ & $\begin{array}{r}32 \\
40 \\
109\end{array}$ & $\begin{array}{r}2 \\
6 \\
13\end{array}$ & $\begin{array}{r}8 \\
7 \\
27\end{array}$ & $\begin{array}{r}5 \\
1 \\
13\end{array}$ & $\begin{array}{r}47 \\
54 \\
162\end{array}$ \\
\hline $\begin{array}{l}\text { Inadequate specimen } \\
\text { No specimen available } \\
\text { Total }\end{array}$ & $\begin{array}{r}12 \\
26 \\
147\end{array}$ & $\begin{array}{r}1 \\
0 \\
14\end{array}$ & $\begin{array}{r}2 \\
6 \\
35\end{array}$ & $\begin{array}{r}1 \\
2 \\
16\end{array}$ & $\begin{array}{r}16 \\
34 \\
212\end{array}$ \\
\hline
\end{tabular}


Table 2 Reclassification of histopathology and history of exposure* to asbestos in 134 men and women by site of original tumour

\begin{tabular}{|c|c|c|c|c|c|c|c|}
\hline & \multicolumn{7}{|c|}{ Pleural and peritoneal $\dagger$} \\
\hline & \multicolumn{3}{|l|}{ Men } & \multicolumn{3}{|l|}{ Women } & \multirow{2}{*}{$\begin{array}{l}\text { Both sexes } \\
\text { total }\end{array}$} \\
\hline & Exposed & Unexposed & Total & Exposed & Unexposed & Total & \\
\hline $\begin{array}{l}\text { Mesothelioma } \\
\text { "Definite" } \\
\text { Probable } \\
\text { Possible (equivocal) } \\
\text { Subtotal } \\
\text { Mesothelioma }\end{array}$ & $\begin{array}{r}1(0) \\
8(1) \\
8(1) \\
17(2)\end{array}$ & $\begin{array}{l}3(0) \\
1 \\
3(2) \\
7(2)\end{array}$ & $\begin{array}{r}4(0) \\
9(3) \\
11(1) \\
24(4)\end{array}$ & $\begin{array}{l}0(0) \\
1 \\
0(0) \\
1\end{array}(0)$ & $\begin{array}{l}0(0) \\
0 \\
3 \\
3 \\
3(1) \\
(2)\end{array}$ & $\begin{array}{l}0(0) \\
1 \\
3 \\
4\end{array}\left(\begin{array}{l}0 \\
(2)\end{array}\right)$ & $\begin{array}{r}4(0) \\
10(4) \\
14(2) \\
28(6)\end{array}$ \\
\hline $\begin{array}{l}\text { Other than usual malignant variety } \\
\text { Other cancer }\end{array}$ & $4(1)$ & $2(0)$ & $6(1)$ & $0(0)$ & $5(2)$ & $5(2)$ & $11(3)$ \\
\hline $\begin{array}{l}\text { Favoured } \\
\text { "Definite" } \\
\text { Subtotal }\end{array}$ & $\begin{array}{l}17(1) \\
25(2) \\
46(4)\end{array}$ & $\begin{array}{r}9(0) \\
12(2) \\
23(2)\end{array}$ & $\begin{array}{l}26(1) \\
37(4) \\
69(6)\end{array}$ & $\begin{array}{l}0(0) \\
1(0) \\
1(0)\end{array}$ & $\begin{array}{r}4(3) \\
7(3) \\
16(8)\end{array}$ & $\begin{aligned} & 4(3) \\
& 8(3) \\
& 17(8)\end{aligned}$ & $\begin{array}{l}30(4) \\
45(7) \\
86(14)\end{array}$ \\
\hline Total & $63(6)$ & $30(4)$ & $93(10)$ & $2(0)$ & $19(10)$ & $21(10)$ & $114(20)$ \\
\hline
\end{tabular}

*Exposure assessed by examining work histories for jobs associated with heavy asbestos exposure.

tFigures are listed for the pleural (no parentheses) and peritoneal (with parentheses) sites separately.

mesothelioma in men varied with the type of work. Production and manufacture of asbestos and shipyard work had the greatest proportions of cases designated mesothelioma $(4 / 9,44 \%$ and $8 / 20,40 \%$ respectively). All of the mesotheliomas in shipyard workers originated in the pleura. Insulation and work in heating trades had smaller proportions designated mesothelioma $(2 / 8,25 \%$ and $4 / 20,20 \%$ respectively). Work in the construction industry had the lowest proportion $1 / 12(8 \%)$.

\section{ESTIMATE OF LATENCY AND DURATION OF EXPOSURE}

The average period from first likely exposure to asbestos to diagnosis, for cases designated definite, probable, and possible mesotheliomas, was 37.9 years (range 26-54). This period was 38.7 years for designated cases of pleural mesotheliomas and 34.3 years for cases of peritoneal mesotheliomas. All designated cases of mesothelioma who had had exposure to asbestos were first exposed before 1950.

One of the eight cases designated mesothelioma among men who worked in shipyards had 23 years of potential exposure to asbestos with initial exposure between 1936 and 1940. The other cases from the shipyards had initial exposure occurring between 1941 and 1945, with a mean duration of exposure of 2.5 years (range $1-5)$. The majority $7 / 11(64 \%)$ of the designated male cases among the other asbestos exposed jobs had initial exposure before 1940, five of the seven before 1935. The mean duration of exposure for male cases in jobs other than the shipyards was 20 years (range 1-41 years). Table 4 lists the jobs that entailed under five years of exposure among cases designated as mesothelioma.

\section{ESTIMATE OF INCIDENCE}

Before reclassification of histopathology, the age adjusted incidence for all 212 mesothelioma cases collected was $7 \cdot 0 / 10^{6}$ person years (py) for men and

Table 3 Reclassification of histopathology for 103 men according to job and site or original tumour*

\begin{tabular}{|c|c|c|c|c|c|c|c|}
\hline & Insulation & $\begin{array}{l}\text { Asbestos } \\
\text { product } \\
\text { manufacturing }\end{array}$ & $\begin{array}{l}\text { Heating } \\
\text { trades }\end{array}$ & Shipyards & Construction & Other & Total \\
\hline \multicolumn{8}{|l|}{ Mesothelioma } \\
\hline "Definite" & & & & 1 & & 3 & 4 \\
\hline Probable & 1 & (1) & 2 & 4 & 1 & $1(2)$ & $9(3)$ \\
\hline Possible (equivocal) & & & $1(1)$ & 3 & & & $11(1)$ \\
\hline & $2(0)$ & $3(1)$ & $3(1)$ & $8(0)$ & $1(0)$ & $7(2)$ & $24(4)$ \\
\hline Other than the usual & & & & $?$ & & & \\
\hline \multicolumn{8}{|l|}{ Other cancer } \\
\hline Favoured & 1 & 2 & 5 & 4 & $5(1)$ & 9 & $26(1)$ \\
\hline "Definite" & $2(1)$ & 3 & 10 & 6 & $4(1)$ & $12(2)$ & $37(4)$ \\
\hline Subtotal & $4(2)$ & $5(0)$ & $16(0)$ & $12(0)$ & $9(2)$ & $23(2)$ & $69(6)$ \\
\hline Total & $6(2)$ & $8(1)$ & $19(1)$ & $20(0)$ & $10(2)$ & $30(4)$ & $93(10)$ \\
\hline
\end{tabular}

*Figures are listed for the pleural (no parentheses) and peritoneal (with parentheses) sites separately. 
Table 4 Jobs with asbestos exposure in designated cases with under five years' exposure

\begin{tabular}{rll}
\hline Case No & $\begin{array}{l}\text { Duration of } \\
\text { exposure (years) }\end{array}$ & Job \\
\hline 1 & 1 & Shipyard, chipper/cutter, removing old paint \\
2 & 1 & Asbestos products manufacturing plant, labourer \\
3 & 1 & Asbestos cement plant, carpenter \\
4 & 2 & Shipyard, labourer \\
5 & 2 & Shipyard, electrician removing old wiring \\
6 & 2 & Shipyard, electrician \\
7 & 2 & Shipyard, welder \\
8 & 2 & Shipyard, painter reconditioning ships \\
9 & 3 & Shipboard, boiler maintenance \\
10 & 4 & Shipyard, boiler room maintenance and cleanup \\
\hline
\end{tabular}

$1 \cdot 8 / 10^{6}$ py for women. Reclassification of the histopathology, however, indicates that these figures may be overestimates of actual incidence of mesothelioma. Since the age distribution among cases designated as mesothelioma is similar to that of all collected cases of mesothelioma, multiplication of the above rates by the proportion of designated cases $(27.9 \%$ for men, $20.0 \%$ for women) provides a better estimate of incidence. On this basis, our estimate of age adjusted mesothelioma incidence in Los Angeles County is $1.95 / 10^{6}$ py for men and $0 \cdot 36 / 10^{6}$ py for women.

\section{TRENDS IN INCIDENCE}

Before the reclassification of histopathology there was a distinct upward trend of incidence over time, with a peak incidence occurring in 1976. The incidence rates for the designated cases of mesothelioma show a rise in 1975-6 and then decline to pre-1975 levels. No continuing upward trend of incidence is apparent after the histopathology has been reclassified.

\section{Discussion}

The proportion of all collected cases with adequate histopathology that were designated malignant mesothelioma was $42 / 162(26 \%)$. This figure is substantially lower than the $40-70 \%$ acceptance reported in other studies that have reviewed mesothelioma histopathology. ${ }^{6-11}$ Our method of case collection may account for part of the difference. The CSP abstractors examine pathology reports and collect information on all cases with reports mentioning mesothelioma or malignant mesothelioma as definite, probable, or consistent diagnoses, regardless of the method of diagnosis or the subsequent clinical course. Other registries have relied on voluntary reports of verified cases by interested pathologists or clinicians for their initial identification of cases. ${ }^{61011}$ Some of these studies have restricted their cases to those diagnosed as malignant mesothelioma ${ }^{8}$ or diffuse mesothelioma, ${ }^{7}$ to those diagnosed by thoracotomy or necropsy, ${ }^{7}$ or to those fatal cases of mesothelioma known to pathologists. ${ }^{6}$ These more highly selected series of cases are likely to have more agreement between pathologists of record and review pathologists than in our series.

In addition, most of these studies are reported without clearly stated criteria for evaluation of histopathology. Therefore, we are unable to compare our histopathological criteria with those used in other studies. A detailed description of our pathology findings will be reported separately.

Several studies with high proportions of cases accepted as mesothelioma have incorporated information from clinical or occupational histories into the histopathological interpretation. ${ }^{6-9} \mathrm{~A}$ history of exposure to asbestos, however, may bias the interpretation of the histopathology towards accepting the diagnosis of mesothelioma. Our approach, which includes blinding the pathologist to the clinical and exposure histories, eliminates the bias that may result from knowledge of the exposure history.

The increasing occurrence of mesothelioma and the shared histological features of mesothelioma and other tumours have been well publicised and may lead pathologists to consider the diagnosis of mesothelioma more frequently when examining tissue of adenocarcinoma or sarcomas. The results of our study suggest that this explanation may be important in women among whom exposure to asbestos was uncommon. A tendency for physicians and pathologists to diagnose mesothelioma if the patient has a history of exposure to asbestos or if asbestos bodies are noted may have occurred in our male cases, among whom exposure was very common. The high prevalence of exposure to asbestos in cases designated as other cancer (favoured or definite) may also be explained in part by the presence of other asbestos associated tumours in this group.

Mesothelioma, however, is a rare tumour. A history of exposure to asbestos is apparently a poor predictor of the presence of mesothelioma because 
exposure to asbestos is common. In our series of cases of highly selected thoracic and abdominal neoplasms only $20 / 71(28 \%)$ of those exposed to asbestos were designated as mesothelioma and a substantial proportion were thought to be other types of cancer.

The higher proportion of designated cases in shipyard and asbestos product manufacturing workers in our study compared with people in other jobs is consistent with the unusually high levels of exposure thought to occur in these trades. The lower proportions of cases in other asbestos exposed jobs are consistent with expectations of lower levels of exposure. The low proportion of cases in construction workers may reflect misclassification of exposure due to the inclusion of many people in construction trades who were either unexposed or not heavily exposed. These findings of higher proportion of designated mesothelioma is the more heavily exposed workgroups supports the validity of our reclassification of histopathology. The detail of the occupational histories obtained from family members of the subjects was often insufficient to determine exposure to asbestos in other jobs with known possible exposure (garage work, building maintenance, sheet metal work, rubber or plastic manufacturing, oil or chemical refinery work) (J S Siegel, as above). Because of this, our study underestimated these exposures to asbestos.

The age adjusted incidence rates for cases designated as mesotheliomas in our study are lower than rates reported in other studies of mesothelioma. Hinds, on the basis of cancer registry data without histopathological verification, estimated the incidence rates in the United States, age adjusted to the 1970 population, to be $4 \cdot 4-11 \cdot 1 / 10^{6}$ py for men and $1 \cdot 2-3 \cdot 8 / 10^{6}$ py for women. ${ }^{12}$ The highest rates were in areas where shipbuilding was a prominent industry. For the Third United States National Cancer Survey, age adjusted incidence rates for mesothelioma without histopathological verification were estimated to be $4 \cdot 91 / 10^{6}$ py among men and $2 \cdot 32 / 10^{6}$ py among women. ${ }^{2}$ Using histopathological verification, McDonald and McDonald reported age adjusted incidence of fatal mesothelioma in the United States in 1972 to be $2 \cdot 74 / 10^{6}$ py for men and $0 \cdot 75 / 10^{6}$ py for women. ${ }^{2}$ They thought that these figures underestimated the incidence of mesothelioma by about $50 \%$ because of the higher figures published in the Third United States National Cancer Survey.

Our data suggest that estimates of mesothelioma incidence using either population based cancer registries or other records, without histopathological verification, may substantially overestimate incidence. The degree of over estimation probably depends on the physician's awareness of mesothelioma as a possible diagnosis and the frequency of exposure in the population.

It is unlikely that Los Angeles County has a lower incidence of mesothelioma than other areas of the United States. McDonald and McDonald found the highest United States incidence for mesothelioma in the Pacific states. ${ }^{2}$ Shipbuilding and repair is a prominent industry along the coast of Los Angeles County, and exposure in this industry accounts for about $40 \%$ of the reported exposure among exposed cases with verified mesothelioma.

Newhouse and Wagner reported that mesothelioma has been mistaken for primary gastrointestinal tumours, lung cancer or carcinomatosis among asbestos workers in the past. ${ }^{13}$ We do not know the number of cases of mesothelioma in Los Angeles County that were not collected for our study because of diagnosis as other primary tumours. The number, however, may be small because of the current awareness of mesothelioma, its characteristic clinical manifestations, and the apparent tendency of pathologists to accept tumours from other primary sites as mesothelioma.

Our interpretation of pathology may overestimate or underestimate the actual number of mesotheliomas. Bias in interpretation would affect the number of cases designated as mesothelioma but is unlikely to affect time trends of incidence. The absence of a clear trend of increasing incidence over the period of this study conflicts with other reports of increasing incidence. ${ }^{12}$ It is unlikely that the CSP is missing greater proportions of mesotheliomas as years pass, thus masking an upward trend. The time between heavy use of asbestos in the second world war and this study is slightly less than the mean latent period for the tumour. We may have studied a period of fairly stable incidence preceding an increase of mesothelioma occurrence expected from the 1940s exposure in shipyards. Prediction of the number of cases of mesothelioma in men first exposed to asbestos during the second world war based on our data is the subject of another paper. ${ }^{14}$

Our reinterpretation of the pathology represents the view of a pathologist who has had extensive experience with mesothelioma. It is well known that there is extensive interobserver variability in diagnosing this tumour. If the reclassification were done by another pathologist or by a panel of pathologists the number of cases accepted as mesothelioma would vary. Therefore this study should not be considered as a definitive assessment of the number of cases of mesothelioma. Instead, the study is a further definition of the problem of interpretation of pathology applied to population based data on the occurrence of mesothelioma. We emphasise that 
there was uncertainty regarding the diagnosis of mesothelioma in several of the original diagnoses from the local hospitals. This study highlights the need for a more uniform definition of mesothelioma, a more uniform application of the presently available criteria and methods for designating tumours mesothelioma, and development of more precise discriminants for identifying neoplastic mesothelial cells so that the occurrence and causes of these tumours can be assessed more accurately.

This work was supported by the American Cancer Society (grant SIG-1), the National Cancer Institute (grant PO-1 CA17054), and the Hastings Foundation.

\section{References}

' Fraumeni JF Jr, Blot WJ. Lung and pleura. In: Schottenfeld D, Fraumeni JF Jr (eds). Cancer epidemiology and prevention. Philadelphia: WB Saunders Co, 1982:564-82.

${ }^{2}$ McDonald JC, McDonald AD. Epidemiology of mesothelioma from estimated incidence. Prev Med 1977;6:426-46.
${ }^{3}$ McDonald AD. Mesothelioma registries in identifying asbestos hazards. Ann NY Acad Sci 1979;330:441-54.

${ }^{4}$ Hisserich JC, Martin SP, Henderson BE. An areawide cancer reporting network. Public Health Rep 1975;90:15-7.

${ }^{5}$ Mack TM. Cancer surveillance program in Los Angeles County. Natl Cancer Inst Monogr 1977;47:99-101.

- McDonald AD, McDonald JC. Malignant mesothelioma in North America. Cancer 1980;46:1650-56.

' Owen WG. Mesothelial tumors and exposure to asbestos dust. Ann NY Acad Sci 1965;132:674-84.

${ }^{8}$ Greenberg M, Lloyd-Davies TA. Mesothelioma register 1967-8. Br J Ind Med 1974;31:91-104.

- Zielhuis RL, Versteeg JPJ, Planteijdt HT. Pleural mesothelioma and exposure to asbestos. Int Arch Occup Environ Health 1975;36:1-18.

${ }^{10}$ Bignon J, Sebastien P, DiMenya L, Payan H. French mesothelioma register. Ann NY Acad Sci 1979;330:455-66.

" Planteydt HT. Netherlands mesothelioma register. Ann NY Acad Sci 1979;330:467-71.

${ }^{12}$ Hinds MW. Mesothelioma in the United States - incidence in the 1970s. JOM 1978;20:469-71.

${ }^{13}$ Newhouse ML, Wagner JC. Validation of death certificates in asbestos workers. Br J Ind Med 1969;26:302-7.

${ }^{14}$ Peto J, Henderson BH, Pike MC. Trends in mesothelioma incidence in the United States and the forecast epidemic due to asbestos exposure during World War II. Banbury report 9. In: Peto R, Schneiderman M, eds. Quantification of occupational cancer. New York: Cold Spring Harbor Laboratory, 1981:51-69. 